\title{
Prevalence of Depression in Animal Model of High Fat Diet Induced Obesity
}

\author{
Muhammad Farhan*, Hamna Rafiq and Hira Rafi
}

\author{
Neurochemistry and Biochemical Neuropharmacology Research Unit, Department of Biochemistry, \\ University of Karachi, Karachi, Pakistan
}

\begin{abstract}
The prevalence of obesity is substantially increased in developing countries and it is considerably associated with type 2 diabetes (T2DM), dyslipidemia, and hypertension. These symptoms are clustered to form metabolic syndrome. In accordance with the Researchers opinion, obese people are more likely to suffer from depression, a mental affliction that appears due to chronic stress, disturbs thoughts, behavior, and feelings. It has been addressed that the physiological impairments which are undergoing due to obesity can affect the metabolic activities which in turn give impact on brain and affect it's functioning, because obesity itself seems to constitute a chronic stressful state thus, exacerbates the risk of depression. Present study intended to illuminate the anticipated links between obesity and stress. To make possible the study, animal model of obesity was accomplished by subjecting the Albino wistar rats with energydense diet (high fat diet) for 5 weeks; later on, chronic mild stress paradigm was implemented along with high fat feeding for 2 weeks. As expected, high fat feeding increased the adiposity in rodents. Obese animals presented the depressive symptoms more prominent than normal fat feeding rats. Present findings suggest that obesity could increase the depressive symptoms potentially involve in the recruitment of depression.
\end{abstract}

Keywords: High fat diet, Obesity, CMS, Depression.

\section{INTRODUCTION}

The physiological metabolism, undergoing inside the body, are extensively affected due to obesity. Obesity is considered as a medical condition, characterizes as abnormal or excessive fat accumulation that may impair health. It proceeds when energy uptake exceeds the energy expenditure or physical activity, leads to the enlarge store of body fat, particularly in adipose tissues. Although it is also interpreted that obesity is the result of consuming diet which is rich in fat [1] and significantly promotes other chronic diseases such as type 2 diabetes and cardiovascular disease [2, 3]. Beside these clinical diseases it is also thought to be a signal for depression [4], it has been addressed that the physiological impairments which are undergoing due to obesity can affects the metabolic activities which in turns give impact on brain and affect its functioning thus, exacerbates the risk of depression. As a consequences, the higher levels of depression in obese people were found $[5,6]$ since obesity itself seems to constitute a chronic stressful state and may cause HPA axis dysfunction [7]. There is a mutual relationship between obesity and depression as obese individual is prone to be at higher the risk of depression [8]. Moreover, stress induced chronic stimulation of the hypothalamic-pituitary-adrenal (HPA) axis plays a potential role in the development of obesity. The HPA

\footnotetext{
*Address correspondence to this author at the Neurochemistry and Biochemical Neuropharmacology Research Unit, Department of Biochemistry, University of Karachi, Karachi, Pakistan;

E-mail: farhankamali@uok.edu.pk
}

axis is not only the regulator of stress response, but is also tightly conducting appetitive behaviors [9]. Depressive symptoms are associated with weight gain because depression and obesity both are responded by the activity of HPA axis [10].

Under normal condition, adipocytes produce a hormone named as leptine which has influence on body weight through the regulation of fat storage inside the adipocytes. The level of leptin is observed to correspond with body fat [11] it regulates food intake through effect on hypothalamus to decrease food intake and increase energy expenditure [12]. Although leptin regulates the appetite but in obese individuals signaling of leptin is attenuated and they exhibit leptin resistance [13]. It has also been addressed that hypothalamic leptin receptor gene expression is suppressed in obesity [14]. CRH is found to be regulated by leptin, a hormone of HPA axis, since leptin signaling is resist in obesity $\mathrm{CRH}$ level will no longer regulate which in turns leads to the dysfunctioning of HPA axis [15]. Elevated level of cortisol, due to hyperactive HPA axis may alter different regions of brain and negatively affects the 5-HT metabolism [16] which has influence on body weight by suppressing appetite and reducing fat consumption [17].

\section{METHODS AND CHEMICALS}

\section{Animals}

24 male Albino Wistar rats weighing $120-180 \mathrm{gm}$ were purchased from The Dow University of Health and Sciences, Karachi, Pakistan and housed in individual cages and allowed to acclimatize to their surrounding @ 2015 Lifescience Global 
with temperature $\left(25 \pm 2^{\circ} \mathrm{C}\right)$ for one week. Animals had free access to a normal standard diet during acclimatizing time before starting experiment. All animal experiments, approved by the Institutional Ethics and Animal Care Committee, were conducted in strict accordance with the National Institutes of Health Guide for Care and Use of Laboratory Animals. All treatments and behavioral monitoring were performed in a balanced design to avoid order and time effects.

\section{Experimental Protocol}

Rodents were randomly divided into two equal groups, Normal Fat Diet (NFD) and High Fat Diet (HFD). According to the groups they treated with respective diet for 5 weeks. Afterwards, animals exposed to the schedule of chronic mild stress for next 2 weeks. Food intake, body weight, behavioral activity in familiar, novel as well as anxiogenic environment was monitored after $1^{\text {st }}$ and last stress.

\section{Composition of High Fat Diet}

The normal diet group were fed a standard rat chow containing $4 \%$ fat, $67 \%$ carbohydrate, and $19 \%$ protein; whereas the HFD or high fat diet animals treated with a diet containing $35 \%$ fat, $26 \%$ carbohydrate, and $26 \%$ protein. Dietary treatment was going as longer for 5 weeks. High-fat diet was designed in our laboratory. The high fat diet was rich in calories (high-fat diet $=5.2$ $\mathrm{kcal} / \mathrm{g}$ versus standard diet $=3.8 \mathrm{kcal} / \mathrm{g}$ ).

\section{Chronic Mild Stress}

Table 1: CMS Type and Duration

\begin{tabular}{|c|c|c|}
\hline Days & Stress & Duration \\
\hline \hline 01 & Cold stress $4^{\circ} \mathrm{C}$ & 2 hours \\
\hline 02 & light dark cycle & 2 hours \\
\hline 03 & Cage agitation & 2 hours \\
\hline 04 & White Noise stress & 2 hours \\
\hline 05 & Light stress & 2 hours \\
\hline 06 & Water deprivation & 12 hours \\
\hline 07 & Tilted cage & 3 hours \\
\hline 08 & Inescapable tail & 1 hours \\
\hline 09 & Wet cage & 1 hours \\
\hline 10 & Crowding & 2 Hours \\
\hline
\end{tabular}

\section{Behavioral Assessment}

\section{Food Intake}

A weighed amount of food was placed individual cages and food intake monitored 24 hours of $1^{\text {st }}$ first stress and then last stress. Intake of food was monitored by placing the weighed amount of food in the Hooper of each animal's cage and measurement is done by weighing the food which was left at the time of measurement.

\section{Body Weight}

Changes in body weight were monitored to find out the effect of stress in obese rats. Each animal was allowed to sit with all four paws in the centre of a basket which was already placed in the balance machine to weigh the animals.

\section{Locomotive Activity}

Locomotive activity of rats was monitored in the familiar environment or activity box. The apparatus consists of square shape activity cage $(26 \times 26 \times 26$ $\mathrm{cm}$ ), bedded with saw dust to provide familiar environment which is present in their cage. The rats placed in the center of activity cage and locomotive activity was monitored over the time period of 10 minutes and the number of cage crossing was noted during this period [18].

\section{Exploratory Activity}

To monitor the changes in locomotor/exploratory activity caused by the chronic mild stress Open field activity test is used for providing novel environment. This environment differs from home cage. It is used to explore the emotionality [19]. Animals were placed individually in the center of open field; consist of square area $76 \times 76 \mathrm{~cm}$ with opaque walls $42 \mathrm{~cm}$ high. The floor is design with 25 equal squares. The time which was taken by animal to move on the center of the square was noted and then, in next 5 minutes the crossing of squares with all four paws was counted.

\section{Anxiolytic Model}

Crawley and colleagues introduced light/dark transition test for assessment of anxiolytic activity [20]. Apparatus consist of two equal compartments ( $26 \times 26$ $x 26 \mathrm{~cm}$ ), floored with the saw dust, one of the compartment is exposed into the light and second compartment is in dark. To monitor the activity a rat is place in the centre of the light compartment of the box. Entries and time spent with all four paws in the light compartment were monitored for a cut off time of 5 minutes [21]. Increased number of entries and time spent in light compartment are used as an indicator of reduced anxiety states [22].

\section{Statistical Analysis}

Results are presented as means \pm SD. Data on the effects of chronic mild stress on the food intake, growth 
rate and locomotor activity, exploratory activity and anxiolytic activity were analyzed by three - way ANOVA (repeated measures design). Software used for the analysis was SPSS (version 17). Individual comparisons were made by Newman-Keuls test. Values of $p<0.05$ were considered as significant.

\section{RESULTS}

Figure 1 shows the effect of CMS on body weight and food intake of HFD fed rodents was monitored on next day of $1^{\text {st }}$ and last stress. Analysis on the data of body weight of HFD treated animals after Stress by three-way ANOVA, showed significant effects of HFD $(F=10.235 ; d f=1,12 ; p<0.01)$, Stress $(F=16.787 ; d f=1$, 12; $p<0.01)$ and Days $(F=298.217 ; d f=1,12 ; p<0.01)$. However, interaction among Days, HF diet and stress $(F=0.256 ; d f=1,12)$ were found to be non significant. Exposure to CMS decreased growth rate in HFD as well as in NFD treated rats. Significant decreased was found after last stress $(p<0.05)$. Increased growth rate found in both unstressed as well as stressed animals of HFD group after $1^{\text {st }}$ stress as compared to respectively treated NFD animals. After last stress growth rate decreased in HFD treated animals significantly as compared to NFD treated stressed group animals. In HFD treated animals, growth rate found to be decreased in both unstressed as well as stressed group animals after last stress as compared to respectively treated animas of unstressed or stressed group of $1^{\text {st }}$ day of stress.

Figure 2 shows the effect of CMS on food intake of HFD fed rodents was monitored on next day of $1^{\text {st }}$ and last stress. Data on food intake of HFD treated rats after CMS analyzed by three-way ANOVA (repeated measure design) showed significant effects of HFD $(F=31.920 ; d f=1,12 ; p<0.01)$, Stress $(F=13.134 ; d f=1$, 12; $p<0.01)$ and Days $(F=413.849 ; d f=1,12 ; p<0.01)$. However, interaction among Days, HF diet and stress $(F=0.387 ; d f=1,12)$ were found to be non significant. Post-hoc analysis by Newman-Keuls test showed that food intake decreased after last stress $(p<0.05)$ in both Normal diet treated stressed animals and HFD treated stressed animals as compared to similarly treated
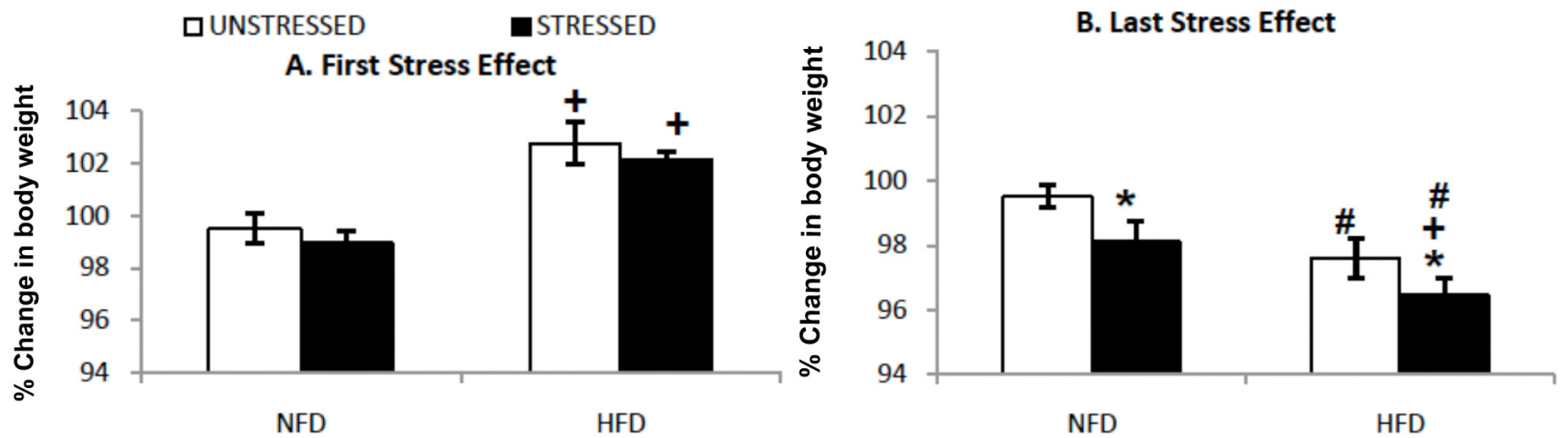

Figure 1: Effect of Chronic mild stress on growth rate of HFD treated Rats. Values are means $+S D(n=6)$ as monitored on next day of $1^{\text {st }}$ and last stress. Significant differences by Newman-Keuls test: ${ }^{*} p<0.05,{ }^{* *} p<0.01$ from respective unstressed animals; $+p<0.01$ from respective NFD treated animals; $\# p<0.05$, \#\#p<0.01 from respective $1^{\text {st }}$ Stress NFD or HFD treated Unstressed or Stressed animals, following three-way ANOVA (repeated measures design).
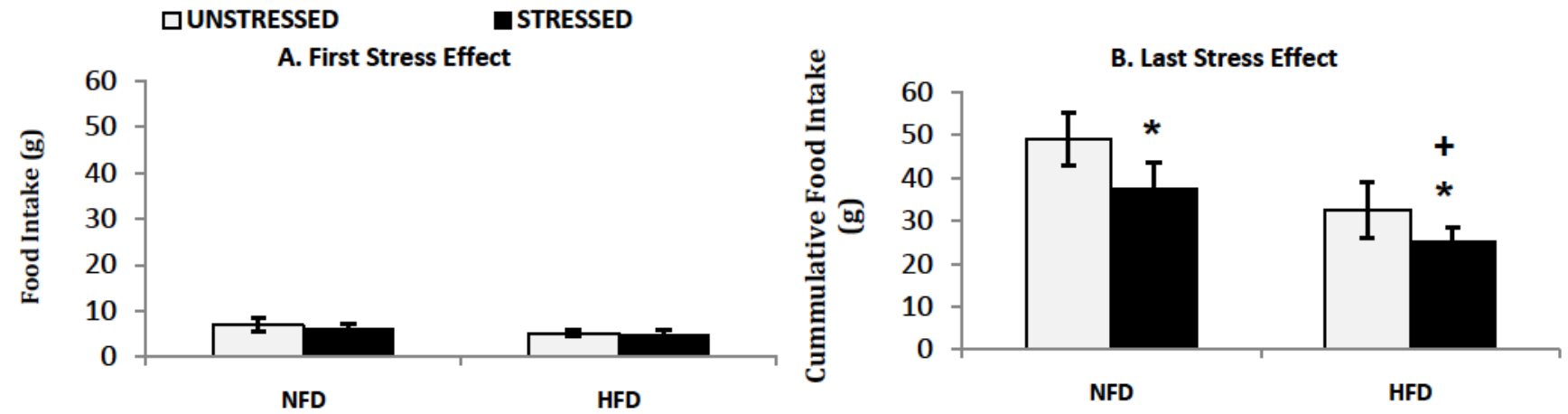

Figure 2: Effect of Chronic mild stress on food intake of HFD treated Rats. Values are means $\pm S D(n=6)$ as monitored on next day of $1^{\text {st }}$ and last stress. Significant differences by Newman-Keuls test: ${ }^{*} p<0.05$, ${ }^{* *} p<0.01$ from respective unstressed animals; $+p<0.01$ from respective NFD treated animals; $\# p<0.05$, \#\#p<0.01 from respective $1^{\text {st }}$ Stress NFD or HFD treated Unstressed or Stressed animals, following three-way ANOVA (repeated measures design). 

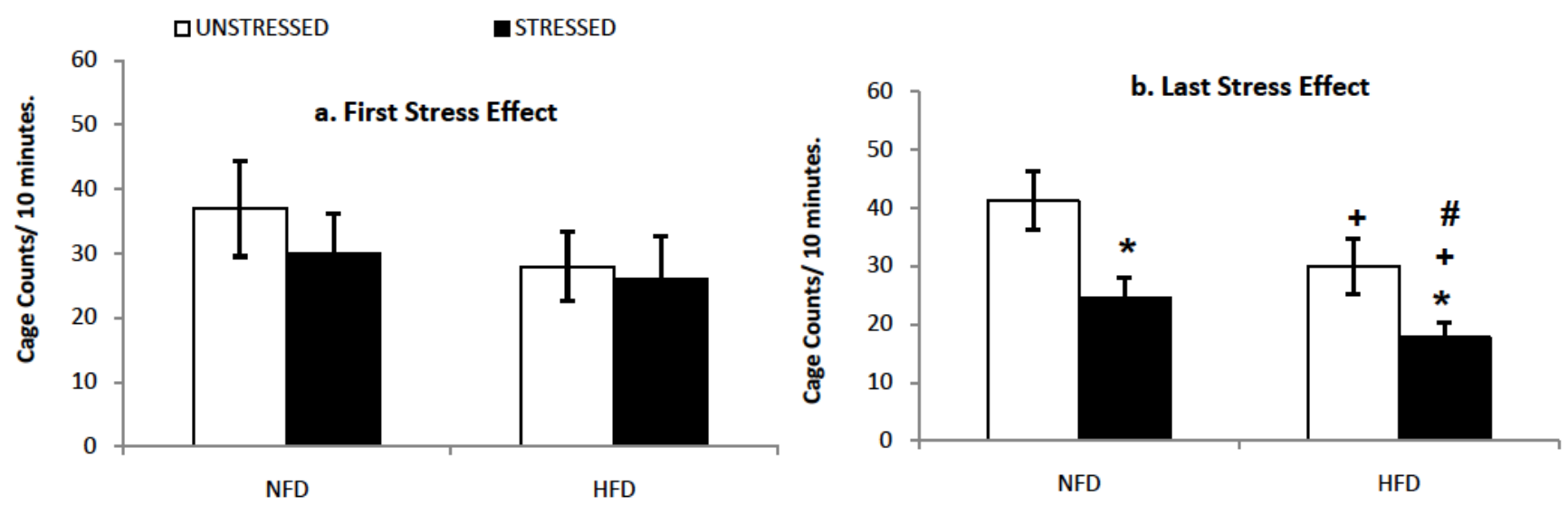

Figure 3: Effect of Chronic mild stress on activity in activity box of HFD treated rats. Values are means \pm SD ( $n=6)$ as monitored on next day of $1^{\text {st }}$ and last stress. Significant differences by Newman-Keuls test: * $p<0.01$ from respective unstressed animals; $+p<0.01$ from respective NFD treated animals; $\# p<0.05, \# \# p<0.01$ from respective $1^{\text {st }}$ Stress NFD or HFD treated Unstressed or Stressed animals, following three-way ANOVA (repeated measures design).

unstressed animals. After last stress significant decreased $(p<0.05)$ in food intake was found in HFD treated animals as compared to NFD treated stressed animals.

Figure 3 shows the effect of CMS on activity of rats treated with HFD in activity box was monitored after $1^{\text {st }}$ and last stress (Figure 3). Analysis of the number of cage crossing of stressed HFD treated animals by three-way ANOVA, showed significant effects of HFD $(F=11.216 ; d f=1,12 ; p<0.01)$, Stress $(F=16.878 ; d f=1$, $12 ; p<0.01)$. However the effect of and Days $(F=1.009$; $\mathrm{df}=1,12)$ and the interaction among Days, HFD and stress $(F=0.006 ; d f=1,12)$ were found to be non significant. Post-hoc analysis by Newman-Keuls test showed that after last stress NFD fed rats significantly decreased their locomotory activity $(p<0.05)$ as compared to HFD fed rats when compared with their respective unstressed controls. It shows NFD fed stressed animals were less active than HFD stressed animals and other unstressed controls.

Figure 4 Shows the effect of CMS on open field activity shows the effect of CMS on number of square crossing in open field in order to monitored exploratory activity of rats treated with HFD was monitored on next day of $1^{\text {st }}$ and last stress. Analysis of the number of square crossing of stressed HFD treated animals by three-way ANOVA, showed significant effects of Days $(F=21.392 ; d f=1,12), \operatorname{HFD}(F=13.148 ; d f=1,12$; $p<0.01)$, Stress $(F=15.596 ; d f=1,12 ; p<0.01)$. However the effect of the interaction among Days, HFD and stress $(F=0.355 ; d f=1,12)$ were found to be non significant. Post-hoc analysis by Newman-Keuls test showed exposure to a schedule of CMS decreased number of square crossed in NFD as well as HFD

\section{a. Number of square crossed}

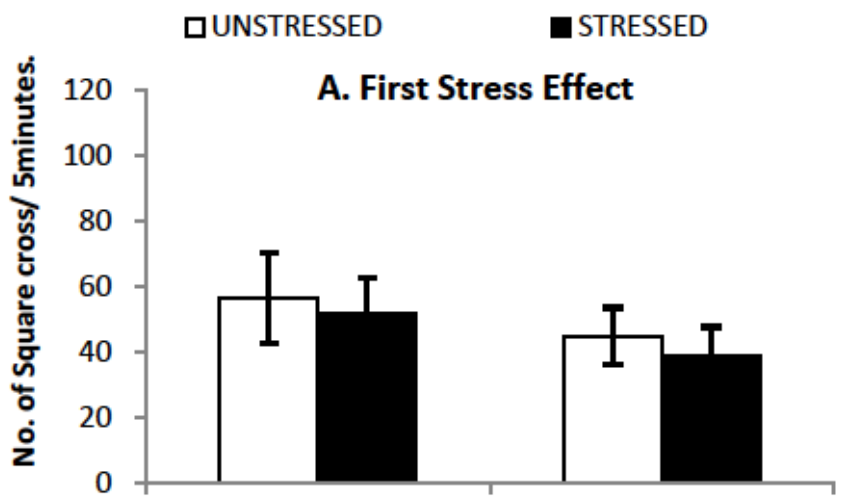

NFD

HFD

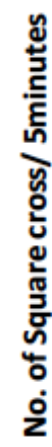

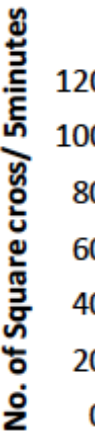

\section{B. Last Stress Effect}

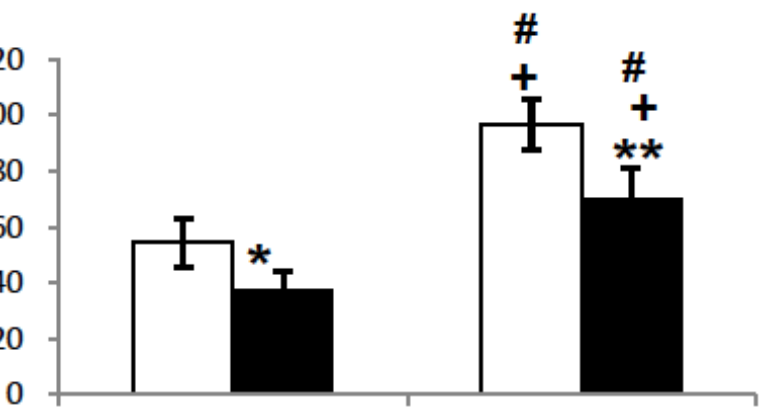

NFD

HFD

Figure 4: Effect of Chronic mild stress on activity in novel environment of HFD-induced obese rats. Values are means \pm SD $(n=6)$ as monitored on next day of $1^{\text {st }}$ and last stress. Significant differences by Newman-Keuls test: ${ }^{*} p<0.05$, ${ }^{* *} p<0.01$ from respective unstressed animals; $+p<0.01$ from respective NFD treated animals; $\# p<0.01$ from respective $1^{\text {st }}$ Stress NFD or HFD treated Unstressed or Stressed animals, following three-way ANOVA (repeated measures design). 

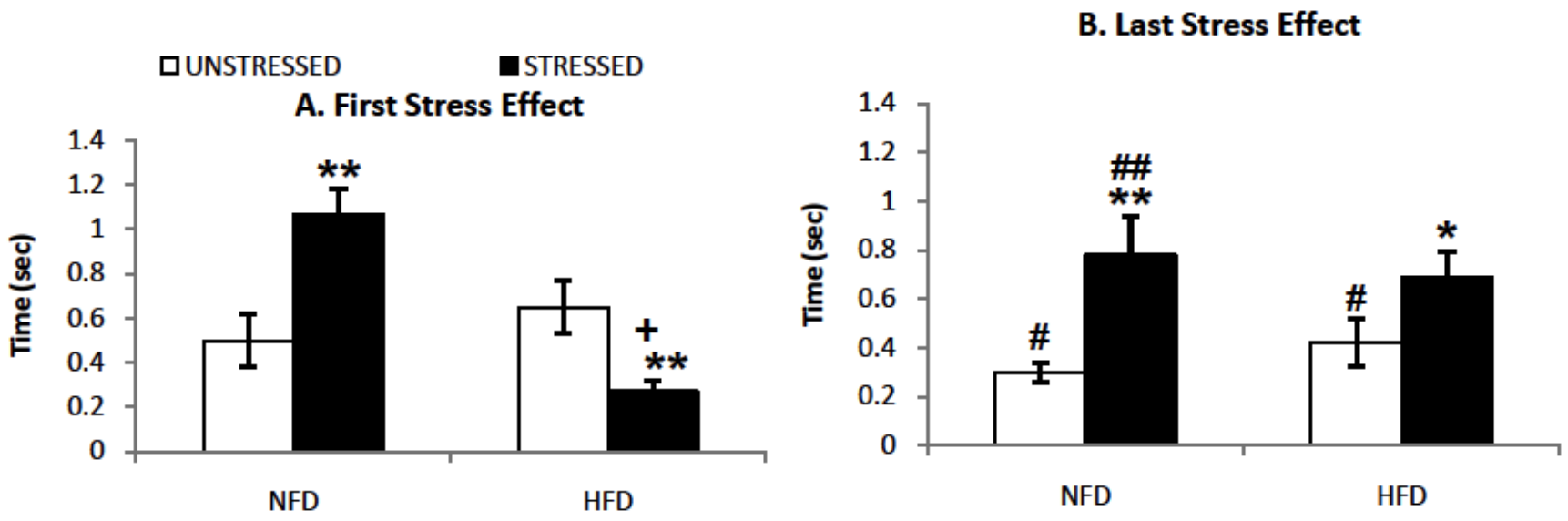

Figure 5: Effect of Chronic mild stress on activity in novel environment of HFD-induced obese rats. Values are means \pm $\mathrm{SD}(\mathrm{n}=6)$ as monitored on next day of $1^{\text {st }}$ and last stress. Significant differences by Newman-Keuls test: ${ }^{*} p<0.05,{ }^{* *} p<0.01$ from respective unstressed animals; $+p<0.01$ from respective NFD treated animals; \#p<0.01 from respective $1^{\text {st }}$ Stress NFD or HFD treated Unstressed or Stressed animals, following three-way ANOVA (repeated measures design).

treated animals. Significant increased in activity was seen in NFD $(P<0.05)$ and HFD $(P<0.01)$ after last stress as compared to similarly treated unstressed animals. In HFD treated animals, activity increased in both unstressed and stressed animals. Significant increase was found after last stress as compared to NFD treated unstressed or CMS animals. After last stress, activity in novel environment increased in HFD treated unstressed as well as CMS animals significantly $(p<0.01)$ as compared to similarly treated unstressed or CMS animals from $1^{\text {st }}$ day of stress schedule.

Figure 5 Shows the effect of CMS on open field activity shows the effect of CMS on latency time in open field in order to monitored exploratory activity of rats treated with HFD was monitored on next day of 1st and last stress. Analysis of the data on latency time of stressed HFD treated animals by three-way ANOVA, showed significant effects of HFD $(F=13.584 ; d f=1$, 12; $p<0.01)$, Stress $(F=22.165 ; d f=1,12 ; p<0.01)$ and interaction among Days, HFD and stress $(F=10.519$; $d f=1,12 ; p<0.01)$. However the effect of Days $(F=3.345 ; d f=1,12)$, were found to be non significant. Post-hoc analysis by Newman-Keuls test showed that CMS exposure increased time required to move in open field of both NFD and HFD treated animals. Significant increased in time was seen after $1^{\text {st }}$ stress in NFD $(p<0.01)$ and after last stress in HFD $(p<0.05)$ as well as NFD $(p<0.01)$ as compared to respectively treated unstressed animals after $1^{\text {st }}$ and last stress. Exposure to chronic stress decreased activity significantly in HFD treated animals as compared to similarly treated unstressed animals after $1^{\text {st }}$ last. After last stress, latency time decreased in NFD treated animals as compared to NFD treated animals of stressed group of $1^{\text {st }}$ day of stress schedule. In HFD
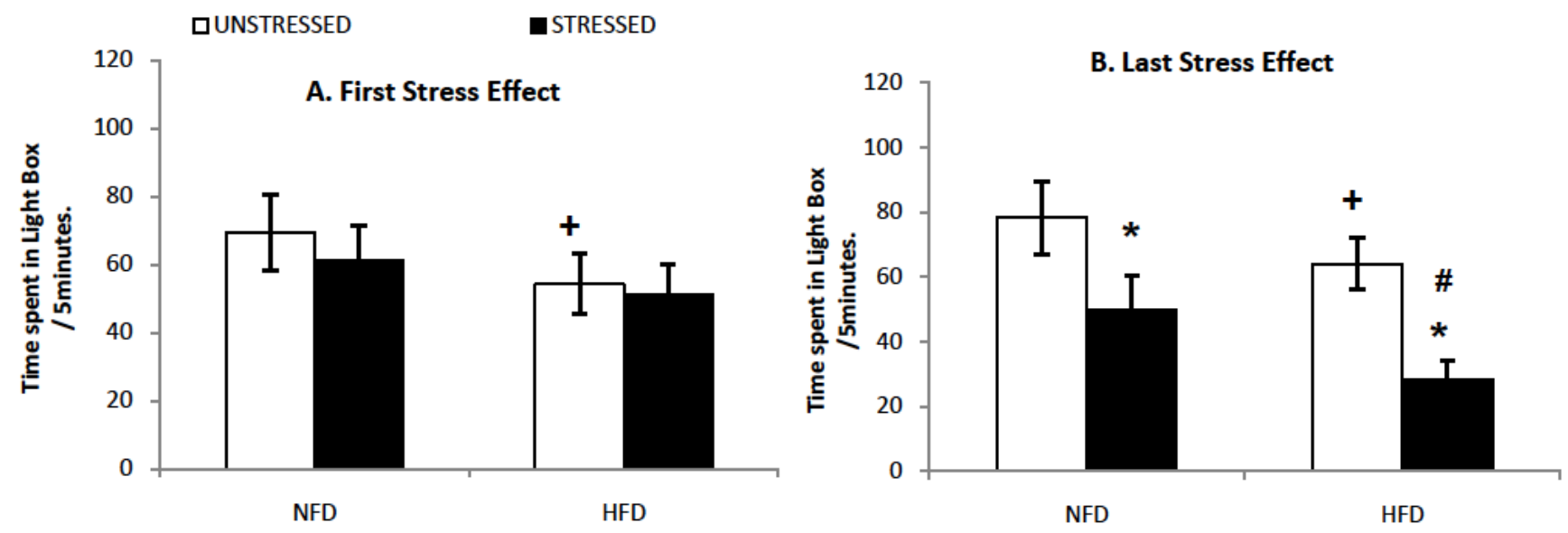

Figure 6: Effect of Chronic mild stress on Light Dark Box activity of rats treated with HFD. Values are means \pm SD ( $n=6$ ) as monitored on next day of $1^{\text {st }}$ and last stress. Significant differences by Newman-Keuls test: ${ }^{*} p<0.01$ from respective unstressed animals; $+p<0.01$ from respective NFD treated animals; \#p<0.01 from respective $1^{\text {st }}$ Stress NFD or HFD treated Unstressed or Stressed animals, following three-way ANOVA (repeated measures design). 
treated animals, decreased activity was seen in unstressed animals on repeated monitoring. Significant decreased was found after last stress as compared to unstressed animals of HFD treated animals from $1^{\text {st }}$ day of stress.

Figure 6 Shows the effect of CMS on time spent in light box in order to explore anxiolytic behavior of rats treated with HFD, as monitored on next day of $1^{\text {st }}$ and last stress. Analysis of the data on time spent of stressed HFD treated animals by three-way ANOVA, showed significant effects of HFD $(F=17.856 ; d f=1$, $12 ; p<0.01)$, Stress $(F=26.951 ; d f=1,12 ; p<0.01)$. However the effect of Days $(F=1.687 ; d f=1,12)$ and interaction among Days, HFD and stress $(F=1.106$; $d f=$ $1,12)$, were found to be non significant. Post-hoc analysis by Newman-Keuls test showed that CMS decreased activity in NFD as well as HFD treated animals. Significant decreased in activity was seen after last stress in HFD $(p<0.01)$ and NFD $(p<0.05)$ treated animals as compared to similarly treated unstressed animals. After last stress, activity decreased in unstressed HFD treated animals as compared to NFD treated unstressed animals of similar day. Time spent in light box by HFD treated animals decreased after last stress significantly $(p<0.05)$ as compared to similarly treated animals of stressed group from $1^{\text {st }}$ day of stress.

\section{DISCUSSION}

The aim of the present study was focus on the association between depression-like state and lipid metabolism in rats submitted to the chronic mild stress with high-fat diet. Present work exposed the obese animal to a schedule of CMS to produce behavioral deficits and revealed the impacts of CMS on obesity, the prevalence of depression in obesity and the metabolic alterations in fat rich body in the adverse situation. For this purpose, a model of high fat dietinduced obesity was applied to laboratory rats. Dietary profile is a crucial factor behind the reason of extraordinary body weight. Weight gain was seen to be higher in rats fed fat rich diet continuously probably due to the insufficient utilization of fats for energy purpose and their excessive storage in adipose tissue [23]. It suggest that high fat feeding proceeds the deposition of fats in adipose tissue which in turns develop leptin resistance, a hormone that regulates body weight by controlling fat accumulation in adipose tissues, thereby exhibit leptine resistance [13]. CMS induced decreased body weight in obese rats is due to hyperactive HPA, present study provides evidence which is supported by another study [24] that body weight of CMS exposed high fat feeding animals was decreased more than normal fat feeding (Figure 1) because exposure to chronic mild stress results in significant behavioral deficits in a wide range of animal models have been resulted to induce significant changes in behavioral parameters [25]. Excessive fat in a diet promotes the accumulation of fats molecules inside the adipose tissues out of proportion, alters their morphology and undergoing mechanisms. Results from present study revealed that consumption of high fat diet induces hyperphagic effects it may be due to fat-rich diets generally increases food intake in male and female rodents regardless of the degree of saturation [26-30]. In present study, Figure $\mathbf{2}$ shows the relation between monoaminergic neurochemistry and macronutrient intake, exposure to CMS reduces food intake but in fat rich animals the effects of CMS are more prominent. CMS induced hypophagia is encouraged by using high fat is reported earlier [24]. CMS induced behavioral deficits in experimental model could be used reliably as animal model of depression [31].

The increased prevalence of obesity has been attributed to a decreased physical activity. In the present study results are suggesting that obesity decrease the physical activity gradually. Different behavioral tests (Figures 3 and $\mathbf{4}$ ), Home cage activity and open field test, provides observation about physical locomotor activity [18]. Adiposity has often seen to negatively associated with physical activity [1]. In Figure 2 results shows that rats with high fat diet intake were shown to be less active physically over the normal diet using rats, it suggests that Stress-induced suppression of home cage locomotor activity was also reduced by obesity it could be due to decreased serotonergic function which is encourage by CMS [16] results the depressive symptoms [32]. Conversely, High fat-induced obese rats have been shown to increase their active behavior in novel environment compared to normal fat using controls (Figures $\mathbf{4}$ and 5). An evidence [33] Supported the idea that high fat feeding are inversely related to anxiety, while anxiogenic condition are also indicated (Figure 6) by high fat induced obesity. Additionally, CMS exacerbates its effect on anxiety so that rats with HFD showed more anxiogenic over the normal diet rats.

\section{CONCLUSION}

Present work concluded that there are considerable impacts of dietary nutrient in the body response towards energy metabolism and behavior as well. It 
does not only participate in the induction of obesity by altering the morphology of adipose tissue, but also impairs the neurochemical mechanisms which holds up the homeostasis and responsible for balance the body under adverse situation. In this regards, fats are more often claimed as responsible for these impairment because, unlike other macronutrients, they are specialized to store inside the tissues, adipose tissue, and initiates metabolic disturbance.

\section{REFERENCE}

[1] Schrauwen P, Westerterp KR. The role of high-fat diets and physical activity in the regulation of body weight. $\mathrm{Br} \mathrm{J}$ Nutr 2000; 84: 417-427. http://dx.doi.org/10.1017/S0007114500001720

[2] Herva A, Laitinen J, Miettunen J, Veijola J, Karvonen JT, Laksy K, Joukamaa M. Obesity and depression: results from the longitudinal Northern Finland 1966 Birth Cohort Study. Int J Obes (Lond) 2006; 30(3): 520-527. http://dx.doi.org/10.1038/sj.ijo.0803174

[3] Ma J, Xiao L. Obesity and depression in US women: results from the 2005-2006 National Health and Nutritional Examination Survey. Obesity (Silver Spring) 2010; 18(2): 347-353.

http://dx.doi.org/10.1038/oby.2009.213

[4] Roberts RE, Kaplan GA, Shema SJ, Strawbridge WJ. Are the obese at greater risk for depression? Am J Epidemiol 2000; 152: $163-170$.

http://dx.doi.org/10.1093/aje/152.2.163

[5] Allison DB, Newcomer JW, Dunn AL, Blumenthal JA, Fabricatore AN, Daumit GL, Cope MB, Riley WT, Vreeland B, Hibbeln JR, Alpert JE. Obesity among those with mental disorders. A national institute of mental health meeting report. Am J Prev Med 2009; 36: 341-350.

http://dx.doi.org/10.1016/j.amepre.2008.11.020

[6] Zhao G, Ford ES, Dhingra S, Li C, Strine TW, Mokdad AH. Depression and anxiety among us adults: Associations with body mass index. Int J Obes 2009; 33: 257-266. http://dx.doi.org/10.1038/ijo.2008.268

[7] Kyrou I, Chrousos GP, Tsigos C. Stress, visceral obesity, and metabolic complications. Ann N Y Acad Sci 2006; 1083: 77-110.

http://dx.doi.org/10.1196/annals.1367.008

[8] Luppino FS, De Wit LM, Bouvy PF, Stijnen T, Cuijpers P, Penninx BWJH, Zitman FG. Overweight, obesity, and depression: a systematic review and meta-analysis of longitudinal studies. Archiv General Psychiatry 2010; 67: 220-229.

http://dx.doi.org/10.1001/archgenpsychiatry.2010.2

[9] Rosmond R. Stress induced disturbances of the HPA axis: pathway to Type 2 diabetes? Med Sci Monit 2003; 9: RA359.

[10] Otte C, Hart S, Neylan TC, Marmar CR, Ya e K, Mohr DC. A meta-analysis of cortisol response to challenge in human aging: importance of gender. Psychoneuroendocrinology 2005; 30: 80-91.

http://dx.doi.org/10.1016/j.psyneuen.2004.06.002

[11] Wang GJ, Volkow ND, Fowler JS. The role of dopamine in motivation for food in humans: implications for obesity. Expert Opin Ther Targets 2002; 6: 601-609. http://dx.doi.org/10.1517/14728222.6.5.601

[12] Lin S, Thomas TC, Storlien LH, Huang XF. Development of high fat diet-induced obesity and leptin resistance in c57b1/6j mice. Int J Obes 2000; 24: 639-646.

http://dx.doi.org/10.1038/sj.ijo.0801209
[13] Myers MG, Cowley MA, Münzberg $H$. Mechanisms of leptin action and leptin resistance. Annu Rev Physiol 2008; 70: 537-56.

http://dx.doi.org/10.1146/annurev.physiol.70.113006.100707

[14] Levin BE, Dunn-Meynell AA, Ricci MR, Cummings DE. Abnormalities of leptin and ghrelin regulation in obesity-prone juvenile rats. Am J Physiol-Endocrinol Metab 2003; 285: E949-E957.

[15] Licinio J, Mantzoros C, Negrao AB, Cizza G, Wong ML, Bongiorno PB, Chrousos GP, Karp B, Allen C, Flier JS, Gold PW. Human leptin levels are pulsatile and inversely related to pituitary-adrenal function. Nat Med 1997; 3(5): 575-9. http://dx.doi.org/10.1038/nm0597-575

[16] Pitchot W, Hansenne M, Pinto E, Reggers J, Fuchs S, Ansseau M. Alpha-2-adrenoreceptors in depressed suicide attempters: relationship with medical lethality of the attempt. Neuropsychobiology 2001; 44(2): 91-4. http://dx.doi.org/10.1159/000054923

[17] Blundell JE, Lawton CL, Halford JC. Serotonin eating behavior and fat intake. Obesity Res 1995; 3: 471S-476S.

[18] Haleem DJ, Samad N, Haleem MA. Reversal of haloperidolinduced extrapyramidal symptoms by buspirone: a time related study. Behav Pharmacology 2007a; 18: 147-153. http://dx.doi.org/10.1097/FBP.0b013e3280dec67f

[19] Hall CS, Ballachey EL. A study of the rat's behavior in a field: a contribution to method in comparative psychology. University of California Publications in Psychology 1932; 6: 112.

[20] Leng G, Russel JA. Learning to cope with repeated stress. J Physiol 1988; 510; 331. Levels in ethanol treated rats. Life Sci 47: 971-979.

[21] Bourin $M$, Hascoet $M$. The mouse light/dark box test. Eur $J$ Pharmacol 2003; 463: 55-65. http://dx.doi.org/10.1016/S0014-2999(03)01274-3

[22] Imaizumi $M$, Suzuki $T$, Machida $H$, Onodera $K$ A fully automated apparatus for a light/dark test measuring anxiolytic or anxiogenic effects of drugs in mice. Jpn J Psychopharmacol 1994; 14: 83-91.

[23] Storlien LH, Huang XF, Lin S, Xin X, Wang HQ, Else PL. Dietary fat subtypes and obesity. World Rev Nutr Diet 2001; 88: 148-154. http://dx.doi.org/10.1159/000059778

[24] Harris RB, Zhou J, Youngblood BD, Rybkin II, Smagin GN, Ryan DH. Effect of repeated stress on body weight and body composition of rats fed low- and high-fat diets. Am J Physiol 1998; 275(6 Pt 2): R1928-38.

[25] Willner $P$. Animal models as simulations of depression. Trend Pharma Sci 1991; 12: 131-136. http://dx.doi.org/10.1016/0165-6147(91)90529-2

[26] Ainslie DA, Proietto J, Fam BC, Thorburn AW. Short-term, high fat diets lower circulating leptin concentrations in rats. Am J Clin Nutr 2000; 71(2): 438-42.

[27] Ghibaudi L, Cook J, Farley C, van Heek M, Hwa JJ. Fat intake affects adiposity, comorbidity factors, and energy metabolism of sprague-dawley rats. Obes Res 2002; 10: 956-963.

http://dx.doi.org/10.1038/oby.2002.130

[28] Harrold JA, Williams G, Widdowson PS. Early leptin response to a palatable diet predicts dietary obesity in rats: Key role of melanocortin- 4 receptors in the ventromedial hypothalamic nucleus. J Neurochem 2000; 74: 1224-1228. http://dx.doi.org/10.1046/j.1471-4159.2000.741224.x

[29] Huang XF, Xin X, McLennan P, Storlien L. Role of fat amount and type in ameliorating diet-induced obesity: Insights at the level of hypothalamic arcuate nucleus leptin receptor, neuropeptide $y$ and pro-opiomelanocortin mRNA expression. Diabetes Obes Metab 2004; 6: 35-44. http://dx.doi.org/10.1111/j.1463-1326.2004.00312.x 
[30] Woods SC, Seeley RJ, Rushing PA, D'Alessio D, Tso P. A controlled high-fat diet induces an obese syndrome in rats. J Nutr 2003; 133: 1081-1087.

[31] D'Aquila PS, Collu M, Gessa GL, Serra G. The role of dopamine in the mechanism of action of antidepressant drugs. Eur J Pharmacol 2000; 405: 365373. http://dx.doi.org/10.1016/S0014-2999(00)00566-5

[32] Joca SR, Padovan CM, Guimaraes FS. Activation of post synaptic $5-\mathrm{HT}-1 \mathrm{~A}$ receptors in the dorsal hippocampus prevents learned helplessness development. Brain Res 2003; 978: 177-184.

http://dx.doi.org/10.1016/S0006-8993(03)02943-3

[33] Prasad A, Prasad C. Short-term consumption of a diet rich in fat decreases anxiety response in adult male rats. Physiology and Behavior 1996; 60(3): 1039-1042.

http://dx.doi.org/10.1016/0031-9384(96)00135-7

Received on 12-04-2015

\section{DOI: http://dx.doi.org/10.6000/1927-5951.2015.05.03.6}

(C) 2015 Farhan et al.; Licensee Lifescience Global.

This is an open access article licensed under the terms of the Creative Commons Attribution Non-Commercial License (http://creativecommons.org/licenses/by-nc/3.0/) which permits unrestricted, non-commercial use, distribution and reproduction in any medium, provided the work is properly cited. 